\title{
Biocomposting of extracted peppermint plant residue (M entha piperita) using red worm, Eisenia fetida and its effect on the growth of Vigna mungo (Urad)
}

\author{
Satyendra M. Singh*, G eeta R. Gangwar, O mPrakash and R achna \\ Vermiculture and Environmental Research Laboratory, Vermiculture and Vermicomposting Centre, Department of Animal \\ Science, Mahatma Jyotiba Phule Rohilkhand University, Bareilly-243 006 (U.P.), INDIA \\ *Corresponding author E-mail: satyendramsingh@rediffmail.com
}

Abstract: The study on biocomposting of extracted peppermint plant residue, Mentha piperita using red worms, Eisenia fetida on the growth of Vigna mungo (Urad) showed that the worms transformed 1:3 waste: dung medium into bio-compost one week earlier from 1:1 and two weeks earlier from 3:1 media. Rate of reproduction of worms was recorded 2.5 times faster in 1:3 medium than that of 3:1 and the number of earthworms was counted 2.09 times more in 1:3 waste: dung medium than that of $3: 1$. It was noticed that the bio-compost transformed from 1:3 waste: dung medium when mixed with soil in $1: 3$ ratio and used as growing medium, showed the maximum shoot length of $V$. mungo $(28.2 \mathrm{~cm})$ and the minimum $(24.3 \mathrm{~cm})$ when it was transformed from 3:1 (waste: dung) medium and used in 1:1 ratio of vermicompost and soil. Results were discussed in the light of known data.

Keywords: Peppermint, Mentha piperita, Bio-composting, Red worm, Eisenia fetida, Vigna mungo

\section{INTRODUCTION}

Amongst the solid organic wastes, plant residue produced as a result of different horticultural and agricultural practices, has posed a significant level of problem of environmental degradation. These wastes alter physico - chemical and biological factors of the soil components at a very slow and steady pace affecting the diversity of soil organisms and its fertility status. Cultivation of aromatic plants and extraction of essential oils from them is one of common agro-practices amongst the farmers. The extracted mentha plants are one of such residues, which are generally burnt after their extraction creating environmental hazards. It has been estimated that the farmers of north India produce approximately 18-20 q/ acre/year mentha wastes (Gangwar, 2009).

In the present study, an attempt has been made to transform extracted mentha plant residue into biocompost by using red worms, Eisenia fetida and see its effect on one of the pulse plant, Vigna mungo. The changes in physico-chemical and biological parameters of waste were analyzed before and after the process of biocomposting. Rate of reproduction and biomass of worms were recorded after the completion of the experiment to see the food preference of the worms.

\section{MATERIALS AND METHODS}

Extracted peppermint plant residue (M entha piperita) has been collected from nearby agricultural lands and chopped into small pieces of $2 \mathrm{~cm}$. size, shade dried for a fortnight to minimize its aromacity. Plant pieces were mixed with cattle dung in the ratio of 1:3, 1:1 and 3:1 separately. Six rectangular plastic tubs (size 43 x 32 x 14 $\mathrm{cm}$.) were prepared for each ratio having $4 \mathrm{~kg}$ mixed medium and subjected to pre-decomposition process for 15 days. Moisture level of each medium was maintained by sprinkling water as and when required. In the first three tubs of each mixed waste material of extracted mentha residue and dung, $10 \mathrm{~g}$ mature (clitellates) red worms, Eisenia fetida were introduced and remaining three of each medium were kept as control, devoid of earthworms. Experiment was carried out at room temperature $\left(20-25^{\circ} \mathrm{C}\right)$ and till the transformation of waste into bio-compost. Cocoons and worms were sorted out from the prepared bio-compost to count their number and weight, respectively. Physico-chemical and biological parameters of waste media and bio-compost were analyzed and quantified using standard methods to see the alterations in the transformed waste due to worm's activity.

Techniques used for different parameters: The percentage of moisture content, water holding capacity and bulk density of each medium were estimated as per the techniques of Saxena (1994), while $\mathrm{pH}$ by Systronics digital $\mathrm{pH}$-meter (make MK VI); percentage organic matter and carbon using Walkley and Black (1947) method; percentage nitrogen was estimated by Kjeldhal method (Dass et al., 2004) and percent phosphorus and potassium by Dass and Jadhav (2004) method. Micronutrients viz., $\mathrm{Zn}, \mathrm{Fe}, \mathrm{Mn}$ and $\mathrm{Cu}$ were estimated using the techniques of Srinivasa Murthy et al. (1999). Biomass of worms was 
taken by an electronic balance (Afcoset, ER-182 A make) and the rate of reproduction of worms was calculated as per Chaudhury et al. (2001).

Preparation of $10 \%$ aqueous extract of bio-compost: It was prepared by dissolving $10 \mathrm{~g}$ bio-compost into $100 \mathrm{ml}$ of tap water. Impact of aqueous extract on the germination of seeds of Vigna mungo (Urad) was assessed (as per the method of Singh (2007). Size of plumule and radicle of germinated seeds was measured after 96 hours. Similar experiments were conducted for all other bio-compost extracts side by side along with the extract prepared by using plane soil.

Preparation of bio-compost: soil media : Impact of biocompost, prepared from different ratios of waste and dung, was assessed by mixing it with the soil in the ratio of 1:3, 1:1 and 3:1 on the shoot length of plant, Vigna mungo (Urad) using earthen pots (surface diameter 11.6 $\mathrm{cm}$ ), in triplicate. Three healthy seeds were sown in at the depth of $1 \mathrm{~cm}$ from the surface in each pot. Moisture of pots was maintained by sprinkling appropriate amount of water alternatively. Shoot length of the grown plants was measured and the data were compared with the plants grown in the pots having soil only.

\section{RESULTS}

Alterations in physico-chemical and biological parameters: Physico-chemical parameters of waste: dung media were analyzed before and after the process of biocomposting (Table 1).

Physical: During the transformation of plant residue, the level of moisture content was altered by $10 \%$, on an average. It may be seen that the $\%$ water holding capacity (WHC) was more in the experimental media (those with worms) than that of their respective controls. It was 1.43 times higher in the bio-compost transformed from 1:3 medium of the waste: dung than that of 3:1 experimental media. Bulk density, an important physical parameters to determine the degree of compactness and aeration status of soil, was found more in the bio-compost transformed from 1:3 (waste: dung) medium and less in the biocompost transformed from 3:1 medium. This difference was 1.44 times higher in 1:3 than that of 3:1 medium. It may further be seen that this increase was significantly more in the experimental samples than that of their respective controls.

Chemical:

$\mathrm{pH}$ and organic matter: In the present studies, worm's activity reduced the level of $\mathrm{pH}$ in the medium where they live. This lowering in $\mathrm{pH}$ was more in 1:1 experimental medium than that of other two media with respect to their controls. In the experimental media, it was 1.07 times in the bio-compost transformed from 1:1 waste: dung medium; while in other two media (1:3 and 3:1), these values were only 1.02 and 1.03 times, respectively.
Percent organic matter and carbon were nearly 3.0 times more in the initial state of waste: dung medium of $1: 3$ which was the maximum; while the minimum i.e., 1.4 times in 3:1 ratio than that of their experimental medium. In experimental control media where worms had not been used, the decrement of $\%$ organic matter and carbon were significantly less than that of experimental media where worms had been used. Comparative analysis of the data of decrement of $\%$ organic matter and carbon indicated that it was 2.33 times, 1.76 times and 1.10 times more in 1:3, 1:1 and 3:1 in the experimental media, respectively, than that of their respective experimental controls, devoid of earthworms.

M acro-nutrients: Nitrogen was increased by $1.26,1.25$ and 0.85 times in 1:3, 1:1 and 3:1 experimental media than that of their respective initial values. These values were 1.16, 1.19 and 1.11 times higher in the experimental media than that of their experimental controls. Interestingly, amount of nitrogen was 1.45 times more in 1:3 experimental medium with respect to $3: 1$ and 1.25 times in $1: 1$. The $\mathrm{C}: \mathrm{N}$ ratio was decreased by 3.64 times in 1:3 experimental medium than that of its respective initial value. It was decreased by 1.62 times only in 3:1 medium. In case of experimental control, this value was 1.32 for $1: 3$ and $3: 1$ media and 1.27 for $1: 1$ medium. Phosphorous was increased by 1.75 times in 1:3, 1.33 times in $1: 1$ and 1.23 times in 3:1 waste: dung ratio of experimental media than that of their initial parameters. However, these values were only 1.15 times in 1:3 and 1.07 times in $3: 1$ ratio of experimental controls. Potassium was increased by 1.52 times in the bio-compost transformed from 1:3 waste: dung ratio and 1.43 times from 1:1 ratio of experimental media from the initial values. In experimental control media, such increase was only 1.28 and 1.22 times in $3: 1$ and $1: 1$ media respectively.

M icro-nutrients: Micronutrients have an important role in cellular respiration, were increased significantly in the transformed waste. The level of Zinc ( $\mathrm{Zn}$ ) was increased by 2.14 times more in $1: 3$ waste: dung medium and 1.73 times more in 3:1 ratio of experimental medium form the initial. Level of such increase was significantly lowered in the experimental controls. Iron $(\mathrm{Fe})$ was increased by 1.41 times in $1: 1$ ratio and 1.12 times in $1: 3$ ratio of experimental media; while in experimental control media, it was 1.27 times more in $3: 1$ and 1.11 times in 1:3 medium with respect to their initial values. Increase in the amount of Copper $(\mathrm{Cu})$ was significant in 1:1 waste: dung medium. Analyses of the data revealed that the maximum increase in copper was 1.62 times in the experimental media and 1.48 times in the experimental control. The minimum increase in its amount was in 3:1 ratio than that of other two media. It was recorded that these values for experimental and experimental controls were 1.42 and 1.24 times, respectively indicating worm's activity. In case of 


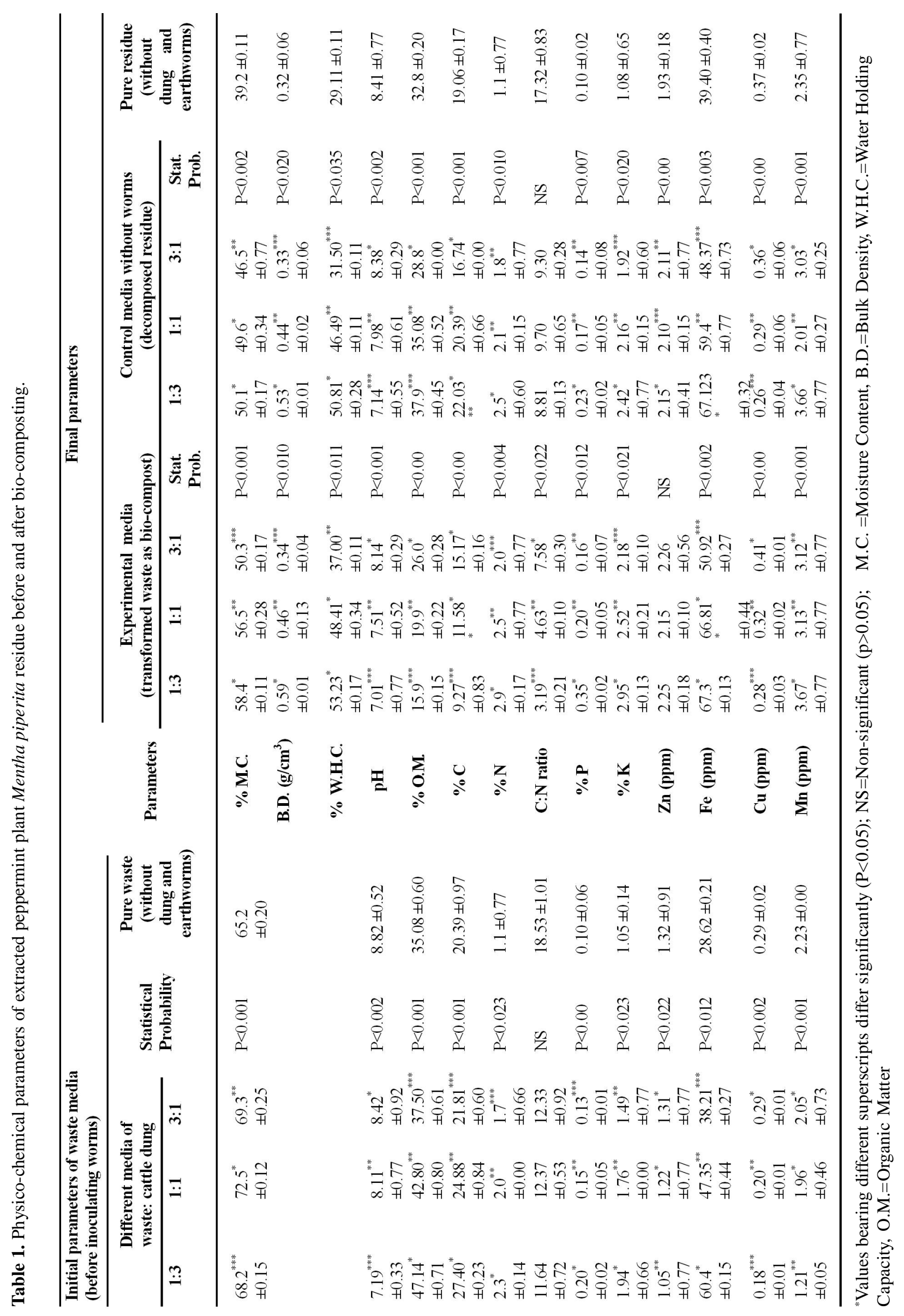


Table 2. Biomass of earthworm, E. fetida before and after biocomposting of extracted peppermint plant residue (M . piperita).

\begin{tabular}{|c|c|c|c|c|c|c|}
\hline \multirow{3}{*}{$\begin{array}{l}\text { Ratio (waste: } \\
\text { cattle dung) } \\
\text { of medium }\end{array}$} & Earthworms & \multicolumn{4}{|c|}{ Earthworms in three size groups (after biocomposting) } & \multirow{3}{*}{$\begin{array}{c}\text { Rate of } \\
\text { reproduction } \\
\text { (young worm } \\
{ }^{1} \text { week }^{-1} \text { ) }\end{array}$} \\
\hline & Clitellates & Clitellates & Non-clitellates & Juveniles & $\begin{array}{c}\text { Total biomass of } \\
\text { earthworms }\end{array}$ & \\
\hline & W eight $( \pm g)$ & W eight $( \pm g)$ & W eight & W eight $( \pm \mathrm{g}$ & W eight $( \pm g)$ & \\
\hline $1: 3$ & 10 & $9.99 \pm 0.10$ & $12.82 * \pm 0.38$ & $4.90^{*} \pm 0.05$ & $27.71^{*} \pm 0.53$ & $2.0^{*} \pm 0.15$ \\
\hline $1: 1$ & 10 & $9.61 \pm 0.26$ & $10.08^{* *} \pm 0.19$ & $4.87^{*} \pm 0.13$ & $24.56^{* * *} \pm 0.58$ & $1.4^{* *} \pm 0.10$ \\
\hline $3: 1$ & 10 & $9.32 \pm 0.70$ & $9.88^{* *} \pm 0.04$ & $4.15^{* *} \pm 0.06$ & $23.35^{* * *} \pm 0.80$ & $0.8^{* * *} \pm 0.05$ \\
\hline $\begin{array}{l}\text { Level of } \\
\text { Probability }\end{array}$ & $P>0.05$ & $P>0.05$ & $P<0.00$ & $\mathrm{P}<0.002$ & $\mathrm{P}<0.001$ & $\mathrm{P}<0.001$ \\
\hline
\end{tabular}

"Values bearing superscripts differ significantly $(\mathrm{P}<0.05)$; Non-significant $=\mathrm{P}>0.05$

Manganese (Mn) too, the maximum increment was in 1:3 ratio in experimental as well as in experimental control media. It was 3.03 times more in both media; while the minimum increment i.e., 1.52 times in $3: 1$ ratio of experimental and 1.02 times more in $1: 1$ in experimental controls.

Biological Parameters:

Impact of dung media:

On cocoon formation, biomass and reproduction: Quality of feed material alters the worm's activity thereby affecting their growth, number and the rate of cocoon production. It may be noted that the number of clitellate earthworms has not been changed during the process of bio-composting (Fig.-1), although, non-clitellates were found more in number in 1:3 waste: dung medium and the minimum in $3: 1$; while juveniles were 1.0 time more in $1: 3$ waste: dung medium than that of $1: 1$ and 1.2 times with that of 3:1 ratio. The maximum number of total worms counted was recorded in 1:3 medium and the minimum in $3: 1$. The total number of cocoons produced was 106 in $1: 3$ waste: dung medium. It was 1.22 and 1.51 times more than that of the number of cocoon produced in 1:1 and 3:1 media, respectively.

The results on the effect of waste media on the biomass of earthworms and their rate of reproduction have been shown in Table 2. It was revealed that 1:3 waste: dung medium was the most congenial feeding medium for the worms as well as for their reproduction. Increase in total biomass of earthworms was 1.2 times more in $1: 3$ waste: dung medium than that of $3: 1(\mathrm{p}<0.001)$. Similarly, rate of reproduction was 2.5 times faster in those worm's that have been kept in 1:3 waste: dung medium than that of in 3:1 medium.

Effect of $10 \%$ aqueous extract of bio-compost on ger mination and shoot length of Vigna mungo: $10 \%$ aqueous extract of bio-compost has promoted the germination rate of radicle and growth of the plumule of seeds of Vigna mungo ( $U$ rad). Germination rate was faster when the seeds were soaked with the aqueous extract prepared from bio-compost of 1:3 ratio medium; while slower in 3:1. Growth rate of radicle was 1.7 times more in the aqueous extract of bio-compost prepared from 1:3 ratio than that of 3:1; while it was only 1.3 times in the case of plumule of the seeds. It may also be noticed that the rate of germination of seeds of V. mungo was very slow, when kept in the extract prepared from the soil alone than that of all types of aqueous extracts of bio-compost (Fig 2). Effect of bio-compost, mixed with different proportions of cattle dung, on the shoot length of experimental plants, V. mungo, showed that when biocompost that was transformed from 1:3 ratio of waste and cattle dung gets mixed with soil in the ratio of $1: 3$ than that of other two media after 60 days of experimentation.(Table 3).

\section{DISCUSSION}

Plant residue alters the physico-chemical and biological factors of the soil if not properly recycled or utilized. In present studies, efforts have been made to transform the mentha plant residue into a bio-manure by introducing red worm, E. fetida into it. It may be noted that in the experimental control media, devoid of worms, the level of moisture content was significantly lowered than that of experimental media, with worms (Table 1). Slower rate of decomposition of plant parts may be one of the causes of difference in the level of moisture content. It may also be seen that worm's activity varied from 50-60\% moisture level of the medium depending upon the waste and dung ratio. Edwards (1988) has also mentioned that 80-90\% moisture content is the optimal level for the maximum activity for E. fetida. Daniel and Karmegam (1999), while working on leaf litter of Azadirachta indica, Ceiba pentandra and Morinda tinctoria, have reported that Eudrilus eugeniae worked well in the range of 60-80\% moisture. Decomposition of rubber leaf litter ( $\mathrm{H}$ evea brasiliensis, var., RRIM 600) required 70-80 \% moisture content for the activity of the worms, Perionyx excavatus, E. eugeniae and E isenia fetida (Chaudhuri et al., 2001). Radhakrishna (2007) has reported that polyculture of $E$. fetida, E. eugeniae and P. excavatus transformed crop 


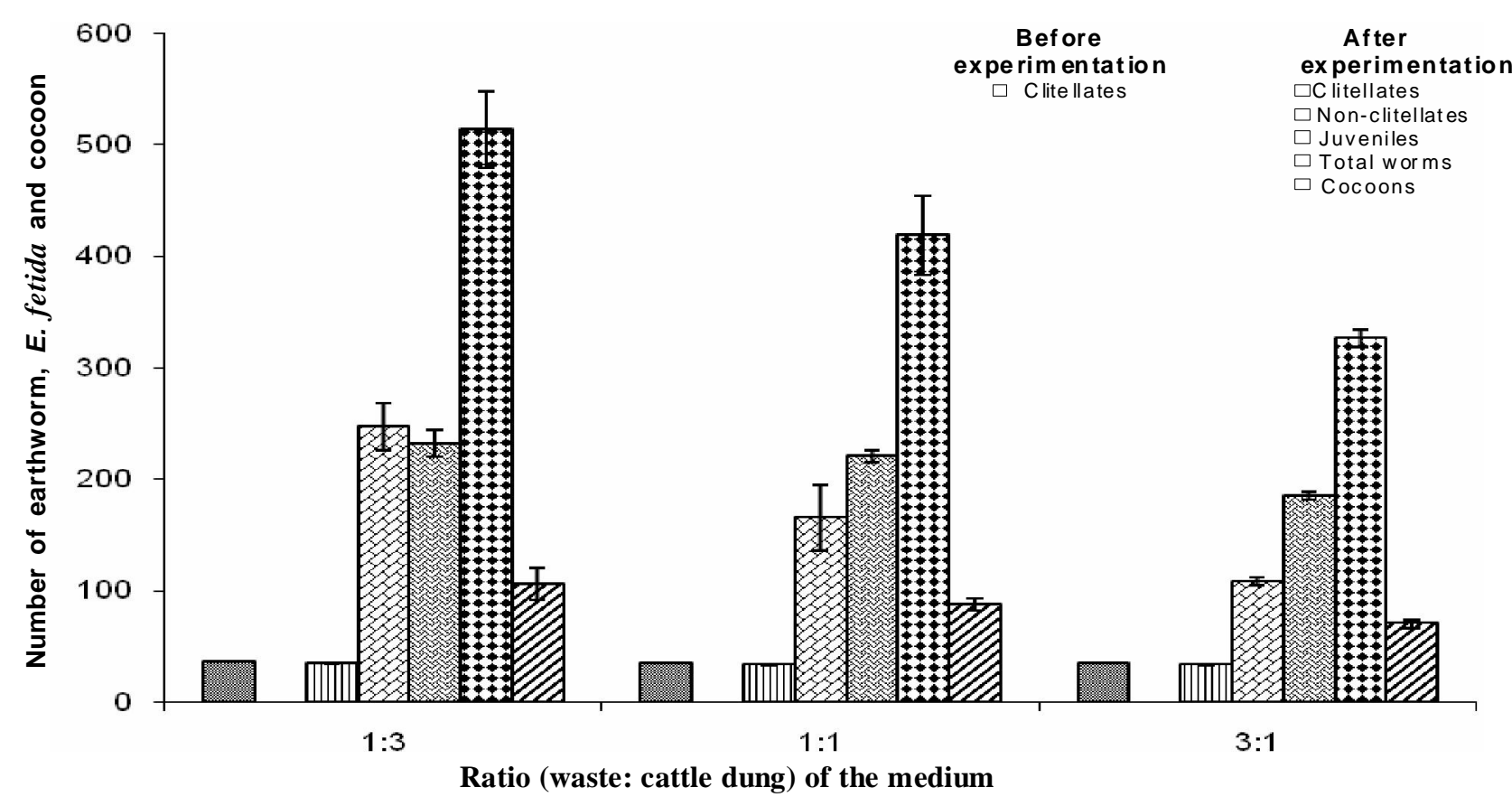

Fig. 1. N umber of earthworm, E. fetida before and after bio-composting of extracted pepper mint plants ( $M$. piperita) as waste and cocoon production. Level of probability (after biocomposting): Rate of growth of particular stage of worm in differ ent media: i) Clitellates $=\mathrm{NS}$; ii) Non-clitellates $=\mathrm{P}<0.010$; iii) J uveniles $=\mathrm{P}<0.015$

residues (green leaves, cover crops and farm residues) into vermicompost when the medium of mixed waste has $70 \%$ moisture level.

Slight increase in the bulk density and water holding capacity (WHC) was observed in the worm-worked media. The maximum increase in the bulk density of bio-compost transformed from experimental medium of 1:3 (waste: cattle dung) was 1.11 times with that of experimental control; while it was 1.03 times only in 3:1 (Table 1). WHC was recorded more in the experimental media than that of experimental controls of 3:1 ratios in all. Difference in the WHC in 3:1 experimental control media might be due to devoid of worms and slower rate of decomposition than that of 1:3 experimental control media. Gupta and Sakal (1967) have reported similar type of changes in WHC while doing comparative study of the physico-chemical composition of earthworm castings of garden and cultivated soils. They have mentioned that castings always have more WHC than that of their respective soils where they live; while castings have less bulk density than that of the parent soil. Although, the results reported here are antagonistic with that of the findings of Gupta and Sakal (1967). It may be due to the dual nature of the experimental set up. In present studies, extracted plant residue of mentha has been taken for its transformation into bio-compost using an epigeic species; while Gupta and Sakal (1967) have measured these two parameters in the garden and cultivated soils for two endogeic species of earthworms, Pheretima posthuma and Eutyphoeus waltoni. However, Dasgupta and Singh (2006) have observed fluctuated values of bulk density and water holding capacity in two different media using cattle dung and soil while working on the response of three species of earthworms, M etaphire posthuma, E utyphoeus woltoni and $E$. fetida to stressed environment and their sustenance in different experimental media.

Worm's activity reduced the $\mathrm{pH}$ of mentha residue. In these studies, it is fascinating to emphasize that $3: 1$ medium of waste: dung has higher $\mathrm{pH}$ than that of $1: 3$. It may be observed that the amount of waste in a particular medium determines the level of reduction of $\mathrm{pH}$.These results supported the findings of Zhenjun (1995), who has reported that $E$. fetida can survive from $\mathrm{pH} 4$ to 11 when kept in cattle dung but the rate of cocoon production was suppressed with higher $\mathrm{pH}$ medium. Although, Edwards and Bohlen (1996) have mentioned that optimal $\mathrm{pH}$ for $\mathrm{E}$. fetida in animal and vegetable wastes was in the range from $>5$ to $<9$. Ansari and Ismail (2001), have decomposed paddy straw along with the cattle dung using three species of composting worms, P. excavatus, $L$. mauritii and E . fetida and observed that the prepared vermicompost has slightly alkaline $\mathrm{pH}$ (7.72) but did not discuss the reasons about such changes in $\mathrm{pH}$. Findings of the present studies showed that the bio-compost has lower $\mathrm{pH}$ than the waste itself and therefore could be used not only as a bio-fertilizer but also as alkalinity reducer in agricultural lands.

Organic matter in a particular medium influences the distribution of earthworms greatly (Edwards and Bohlen, 1996). In present studies, the initial level of organic matter and carbon was decreased much more when extracted Mentha plants were taken along with the cattle dung in 


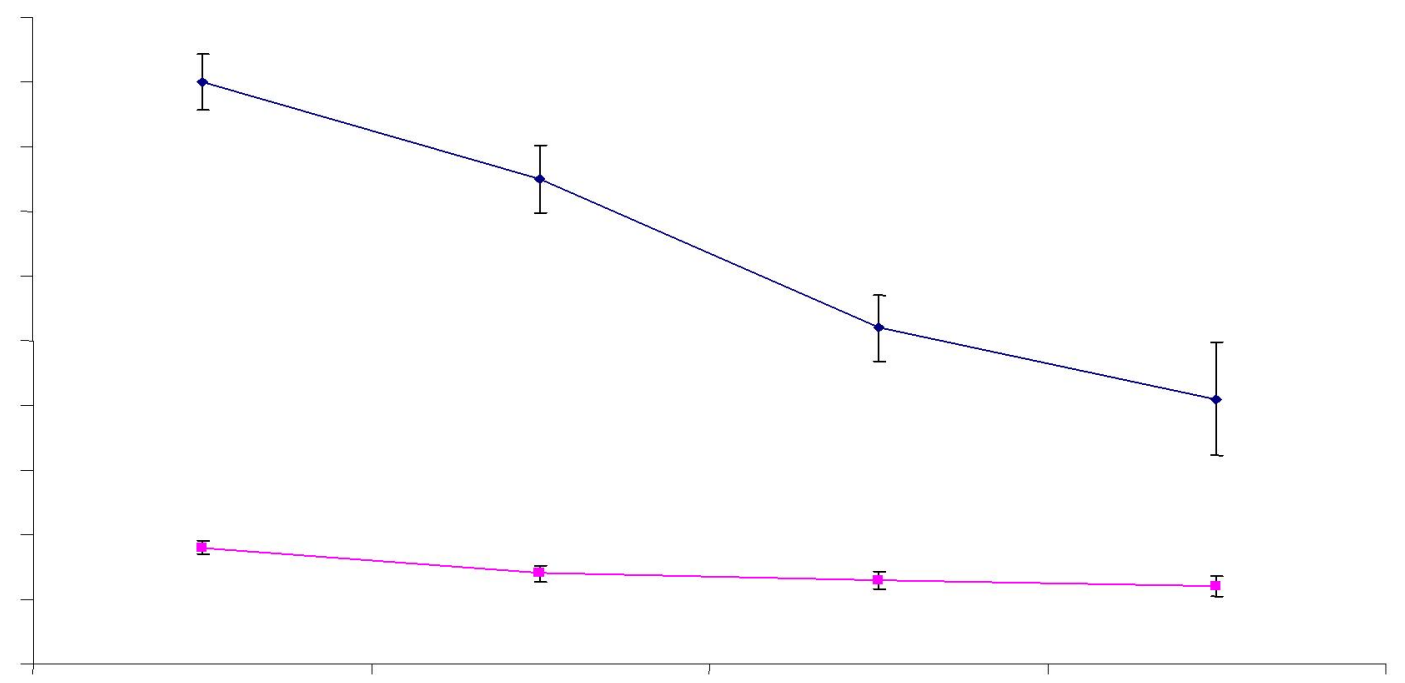

Fig. 2. Rate of germination of seeds of Urad (Vigna mungo) in 10\% aqueous extract of Bio-compost prepared from three experimental media using extracted pepper mint plant residue ( $M$. piperita) with cattle dung ( $S E= \pm 3$ ).

the ratio of $1: 3$ than that of $3: 1$. However, Reddy and Okhura (2004) have claimed an increased level of \% organic carbon in vermicompost transformed from rice straw using worms, 0 ctochaetona phillotti, 0 . rosea and P. excavatus. Although, it is a matter of controversy as when worms fed upon the organic content, lowering in the amount of carbon should be a natural process. It may be possible that the worms used by Reddy and Okhura (2004) may alter the amount of carbon at different levels but these worms have not increased its level.

Earthworms consume large amounts of plant organic matter that contains considerable quantity of nitrogen and much of the nitrogen that they assimilate into their own tissues is returned to the soil in their excretions (Edwards and Bohlen, 1996). Amount of nitrogen was 1.45 times higher in $1: 3$ experimental medium than that of respective 3:1. Daniel and Karmegam (1999) have given the similar findings as reported in the present studies, while working on bioconversion of selected leaf litters using an African epigeic earthworm, E. eugeniae. They have mentioned that $\%$ nitrogen was significantly more in experimental media than that of their respective controls.

Lowering in the level of $\mathrm{C}: \mathrm{N}$ ratio after the transformation of different wastes into vermicompost has been reported by several workers (Mudgal, et al., 2006; Rampal and Sharma, 2002; Daniel and Karmegam, 1999; Senapati and Dash, 1984; Senapati, 1980; Senapati and Dash, 1981a; Edwards and Bohlen, 1996). This was found higher in the waste dung medium of $1: 3$ and lower where the proportion of dung was less than the waste. However, C: $\mathrm{N}$ ratio may be slightly greater in the castings than that of surrounding soil if earthworms ingest carbon rich material content or have greater assimilation efficiencies for nitrogen than carbon (Graff, 1971; Aldag and Graff, 1975). Kale and Krishnamurthy (1981), while working on the factors responsible for the abundance and diversity of earthworms in soil have reported that worm's abundance differed with $\mathrm{C}: \mathrm{N}$ ratio and soil organic matter. They have mentioned that $\mathrm{L}$. mauritii and Pontoscolex corethrurus were abundant in soil with high $\mathrm{C}$ : $\mathrm{N}$ ratio, whereas $P$. excavatus found in the soils of low $\mathrm{C}: \mathrm{N}$ ratio. Increased level of phosphorus has been noticed in the bio-compost transformed by the extracted mentha plants. It was increased by 1.52 times more in the experimental media than that of their respective controls (Table-1). The amount of potassium was increased more in 1:3 waste dung medium than that of $3: 1$. Results of Ansari and Ismail (2001) have also given the similar findings. Sannigrahi and Chakravarthi (2002) have reported that vermicompost transformed from the crop residue has nearly $0.6-1.5 \%$ potassium; while it was slightly more $(0.7-1.9 \%)$ in the vermicompost prepared from weeds. However, Reddy and Okhura (2004) noticed that the vermicompost has less amount of potassium when 0 . rosea and 0 . phillotti worms were used with respect to their controls; while its amount was more when $P$. excavatus was used for vermicomposting. It was also found true when the amount of potassium was quantified in the castings of endogeic earthworms like M. posthuma and E. woltoni. In present findings, level of micronutrients was increased in the bio-compost than in the experimental control mediadevoid of worms (Table 1 ).

It may be noted that 1:3 waste: dung medium was the best feed for the worms, E. fetida, as non-clitellates, juveniles and their total number counted the maximum. 
Table 3. Effect of transformed bio-compost from extracted peppermint plant residue (M . piperita) on the shoot length of Urad (Vigna mungo) in $\pm \mathrm{cm}$.

\begin{tabular}{|c|c|c|c|c|c|c|c|c|}
\hline \multirow{2}{*}{ 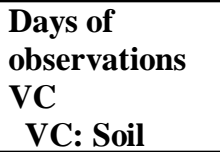 } & \multicolumn{4}{|c|}{ After 30 days } & \multicolumn{4}{|c|}{ After 60 days } \\
\hline & $1: 3$ & $1: 1$ & $3: 1$ & $\begin{array}{l}\text { Stat. } \\
\text { Prob. }\end{array}$ & $1: 3$ & $1: 1$ & $3: 1$ & $\begin{array}{l}\text { Stat. } \\
\text { Prob. }\end{array}$ \\
\hline $1: 3$ & $17.6 \pm 0.13$ & $17.9 \pm 0.41$ & $15.7 \pm 0.98$ & NS & $28.2 \pm 0.71$ & $27.2 \pm 0.10$ & $26.9 \pm 0.78$ & $\mathrm{NS}$ \\
\hline $1: 1$ & $14.5 \pm 0.75$ & $16.1 \pm 0.43$ & $15.7 \pm 0.38$ & NS & $26.9 \pm 0.50$ & $26.9 \pm 0.75$ & $24.3 \pm 0.72$ & NS \\
\hline $3: 1$ & $18.2 \pm 0.10$ & $16.0 \pm 0.78$ & $16.0 \pm 0.65$ & NS & $27.9 * \pm 0.23$ & $27.0 * \pm 0.75$ & $25.7 * * \pm 0.35$ & $P<0.029$ \\
\hline Soil & & $14.1 \pm 0.27$ & & NS & & $25.1 \pm 0.61$ & & NS \\
\hline
\end{tabular}

${ }^{*}$ Values bearing different superscripts differ significantly $(\mathrm{p}<0.05) ;$ NS=Non-significant $(\mathrm{p}>0.05)$

The number of cocoons was produced more in 1:3 medium and less in 3:1 (Fig. 1). It may be noticed that the medium having less amount of mentha and more amount of cattle dung like 1:3 medium supports better growth and reproduction of the worms. Similar results were obtained, when these data were presented in terms of their total biomass and rate of reproduction (young worm ${ }^{-1}$ week $^{-1}$ ) as shown in Table 2. Frederickson, et al. (1997) have reported that the amount of waste material and worm's population altered the rate of cocoon production. While working on the selected freshly shredded green waste (yard waste) using Eisenia andriae in a mechanically turned window system they have mentioned that higher the population of worms, lesser the rate of cocoon production.

Better impact of $10 \%$ aqueous extract of bio-compost on the germination of seeds of Vigna mungo was observed when it was transformed from 1:3 waste: dung medium than that of other two media as well as of plane soil extract (Fig. 2). Singh (2007), while working on the impact of $10 \%$ aqueous extract of three organic wastes (biocon, dairy and pharmaceutical) on the germination rate of Phaseolus aureus and Raphanus sativus, has reported that aqueous extract prepared from 1:3 biocon waste and cattle dung showed better performance on the germination. Although, rate of germination varied in case when dairy waste was taken along with coir pith and water. Aqueous extract of vermicompost transformed from chemical waste (one of the pharmaceutical waste) has better growth impact than its counterpart (the biological waste). Aqueous extract of pure FYM does not perform the role as a good germinator.

Effect of bio-compost on the shoot length of Vigna mungo showed that the bio-compost transformed from 1:3 waste: dung medium, when mixed with soil in the ratio of $3: 1$ acted as a better medium but in the later stage, growth of pants was recorded more in the medium prepared by using bio-compost transformed from 1:3 waste: dung medium in the ratio of 1:3 (Table 3 ).

Earthworms play a catalyzing role in conversion of plant waste in composting which provides essential nutrients to growing plants. Several reports have been made using Indian worms (Kale and Krishnamurthy, 1981; Chaudhury et al., 2001; Reddy and Okhura, 2004 and Mudgal et al., 2006).Vermicompost produced by $E$. fetida transformed from various decaying organic matter have been claimed to be useful as plant growth media for a wide range of plants (Edwards and Burrows, 1988). They have stated that the effect of vermicompost was not only better for seedling emergence but also for the growth of transplanted plants and it is often better than the commercial plant growth media. Recently, effect of vermicompost transformed from the rice straw by using three species of earthworms, viz., $P$. excavatus, 0 . phillotti and 0 . rosea on the growth of Sorghum bicolor has been reported by Reddy and Okhura (2004). They have mentioned that the growth of Sorghum in the mixtures of $75 \%$ of vermicompost produced by $P$. excavatus and $25 \%$ soil was significantly higher than that of the plants grown in the mixtures of vermicompost produced by 0 . phillotti and 0 . rosea and soil, normal compost, soil mixed with chemical fertilizers and sole soil. Tomati et al. (1995) have stated that the earthworm casts and vermicompost influenced the development of plants and promoted stem elongation, root initiation and root biomass, which suggest the linkage between biological effects of vermicompost and microbial metabolites that influence the plant growth and development. Das et al. (2002) have mentioned the effect of integrated application of vermicompost and chemical fertilizer on growth and yield of paddy crop in red soil of south eastern Ghat zone of Orissa. They have noticed that vermicompost integrated treatments have better influence than the FYM integrated treatments at all the level of chemical fertilizer dose. Washimkar et al. (2005) have observed that application of vermicompost at higher doses helped in increasing the leaf yield over lower doses but did not help to reach near the recommended dose of FYM and NPK. In the present studies, growth of shoot length of pulse plants was more in experimental media indicating that vermicompost transformed from plant residue could be used as a biomanure.

\section{REFERENCES}

Aldag, R. and Graff, O. (1975). N-Fraktionen in Regenwurm losung und deren ursprungsbodon. Pedobiologia, 15: 1513. 
Ansari, A. A. and Ismail, S. A. (2001). A case study on organic farming in Utter Pradesh. J. Soil Biol. E col., 21 (1 \& 2). 2529.

Chaudhuri, P. S., Pal, T. K., Bhattacharjee, G. and Dey, S. K. (2001). Suitability of rubber leaf litters (H evea brasiliensis, var., RRIM 600) as vermiculture substrate for epigeic earthworms, Perionyx excavatus, Eudrilus eugeniae and Eisenia fetida. J. Soil Biol. Ecol., 21 (1\& 2) : 36-40.

Daniel, T. and Karmegam, N. (1999). Bio- conversion of selected leaf litters using an African epigeic earthworms, Eudrilus eugeniae. E col. Env.C ons., 5 (3): 277-275.

Das, P.K., Jena, M.K. and Sahoo, K.C. (2002). Effect of integrated application of vermicompost and chemical fertilizer on growth and yield of paddy in red soil of southeastern Ghat zone of Orissa. Environment and E cology, 20 (1): 13-15.

Dass, R.S. and Jadhav, S. (2004). Processing and digestion of feeds and biological materials for minerals for mineral estimation. In Short course on role of mineral and vitamins in live stock health and production, I.V.R.I., India : 186-187.

Dass, R. S., Garg, A. K. Pattnaik, A. K., Dutta, N. and Mehra, U.R. (2004). Short course on role of mineral and vitamins in livestock health and production. Centre of Advanced Studies in Animal Nutrition, I.V.R.I. India: 186-187.

Dasgupta, M. and Singh, S.M. (2006). Response of earthworms to stressed environment and their sustenance in different experimental media. E col. Env. C ons., 12 (2): 351 -356 .

Edwards, C.A. (1988). Breakdown of animal, vegetable and industrial organic wastes by earthworms. Earthworm in Waste and Environmental Management, The Hague, Netherlands, Spa Academic publishing, (24):21-31.

Edwards, C. A. and Bohlen, P. J. (1996). Biology and Ecology of Earthworms. Chapman and Hall, London.426.

Edwards, C. A. and Burrows, S. (1988). The potential of earthworm composts as plant growth media, In: Earthworms in Environmental and Waste Management, (Eds. C A. Edwards and E. F. Neuhauser) SPB Acad. Publ., the Netherlands: 211-20.

Frederickson, J., Butt, K.R., Morris, R.M., Daniel, C. and Edwards, C.A. (1997). Combining vermiculture with traditional green waste composting systems. Soil Biol. Biochem., $29: 725-730$.

Gangwar, G.R. (2009). Bio-remedial measures for solid waste management using earthworm, Eisenia fetida. Ph.D. Thesis submitted to Mahatma Jyotiba Phule Rohilkhand University, Bareilly. p- 191.

Gupta, M. L. and Sakal, R. (1967). A comparative study of the physico- chemical composition of earthworm- castings of the garden and cultivated soil. J . Sci. Res.,B.H.U. 17:213-270.

Graff, O. (1971). Stikstoff Phosphor und Kaliun in der Regenwurmlosung auf der wiesenver suchs flache des
Sollingprojecktes. Ann. Zool. E col. Anim. Special Publ.:50312.

Kale, R.D. and Krishnamurthy, R. V. (1981). Litter Preferences in the earthworms Lampito mauritii. Proc. Indian Acad. Sci. (Anim. Sci.) 90:123-28.

Mudgal, A. K., Sharma, V. and Tiwari, R. K. (2006). Perionyx excavatus: A biological tool to convert local weeds into useful vermicompost. Him. J . Env., 20 (2): 243-45.

Radhakrishna, D. (2007). Organic matter decomposition and vermicompost enrichment technology. In: Earthworms for Solid Waste Management (ed.S.M.Singh) IBDC publication, Lucknow: 51-56.

Rampal, R. and Sharma, D. (2002). Utilization of unused biowaste for production of vermicompost. Him. J. Env., 16 (1): 113-117.

Reddy, M. V. and Okhura, K. (2004). Vermicomposting of rice straw and its effects on Sorghum. Trop. E cology, 145 (2): 327-331.

Sannigrahi, A.K. and Chakravarthi, S. (2002). Beneficial management of organic wastes by vermicomposting. IJ EP 22 (4): 405-08.

Saxena, M. M. (1994). Environmental analysis of water, soil and air. Agro Botanic Publishers: 1-184.

Senapati, B.K. (1980). Aspects of Ecophysiological studies on tropical earthworms (Distribution, population dynamics, production, energetics and their role in the decomposition process, "PhD. Thesis submitted to Sambalpur University, Orissa, India: 151

Senapati, B.K. and Dash, M. C. (1981a). Effect of grazing on the elements of production in vegetation and Oligochaetes of a tropical Pasture, Rev. E col. Biol. Sol., 18 (4): 487-505.

Senapati, B.K. and Dash, M. C. (1984). Influence of soil temperature and moisture on the reproductive activity of tropical pasture earthworms of Orissa: J . Soil Biol. Ecol. (4) : 13-21.

Srinivasa Murthy, C. A., Chidanandappa, H. M. and Nagaraja, M. S. (1999). Laboratory manual for methods of soil plant analysis (SS and AC 607), The University of Agricultural Sciences, Agriculture College, G K V K, Bangalore: 1-108.

Singh, S. M. (2007). Earthworms for solid waste management. International Book Distributing Co. Lucknow: p. 1-242.

Tomati, U., Grappelli, A. and Galli, E. (1995): The hormonelike effect of earthworm casts on plant growth. Biology and Fer tility of Soils, (5) : 288-294.

Walkley, A., and Black, J.A. (1947). Determination of organic carbon in soil. Soil Sci., 37 : 29-38.

Washimkar, S.V., Shinde, P.H., Raut, M. M., Wandile, R.M. and Bhaisare, B.S. (2005). Effect of vermicomposting on the contents of nutrients and yield of mulberry grown on vertisol. J. Soils Crops, 15 (1) : 144-149.

Zhenjun, S. (1995). Earthworm production and nutritive value: Beijing Agricultural Univ., Beijing, China. 243. 